\title{
Eddies in the Southern Mozambique Channel
}

\author{
G.D. Quartly* and M.A. Srokosz \\ Southampton Oceanography Centre, \\ e-mail: gdq@soc.soton.ac.uk; tel: +44-23-8059-6412; fax: +44 23-8059-6400
}

\begin{abstract}
The Agulhas Current system contains one of the world's strongest western boundary currents, and plays an important part in the warm water path of the global thermohaline circulation. However, there have been few surveys of the source regions of the Agulhas Current, and thus little in situ measurement of their variability. Utilizing the more than 5-year record of SeaWiFS data, we examine the eddy activity present in the southern portion of the Mozambique Channel. The two sources of Agulhas input from the central Indian Ocean (southward flow through the Mozambique Channel and westward flow around the southern limit of Madagascar) both show great temporal variability, with no clear seasonal signal.

A number of large (-200 km diameter) anticyclonic rings intermittently propagate poleward along the western edge of the channel, sweeping coastal waters into mid channel. Their passage past Maputo appears to affect the circulation of the lee eddy in the Delagoa Bight. The eastern side of the channel is mainly characterized by cyclonic eddies. These are made manifest in the lee of the southern tip of Madagascar, although it is not clear whether many form there or just develop a visible presence due to entrainment of high chlorophyll coastal waters. Several of these cyclonic eddies then appear to move in west-southwesterly direction. The chlorophyll data do reveal the East Madagascar retroflection on occasions, but do not show clear examples of the pinching off of anticyclonic eddies. However surface waters from the East Madagascar Current may reach the African mainland on occasions when no retroflection is present.
\end{abstract}

\section{Introduction}

The southern end of the Mozambique Channel is the source region for the incipient Agulhas Current, the strongest western boundary current in the southern hemisphere. However there is much debate and research on the origin of the source waters for this current. Contributions are believed to come southward through the Mozambique Channel and westward from the East Madagascar Current (EMC) and also to involve recirculation within a gyre in the southwest of the Indian Ocean (Stramma and Lutjeharms, 1997). As there have been few hydrographic surveys in this region, there are few estimates of the mean transport from these sources, let alone reliable bounds on their variability, either short term or interannual.

There are now extensive records of remotely-sensed data for this region from a number of different satellite sensors, which can be used to make up for some of the shortfall in in situ observations. Section 2 summarises the perceived circulation and physical processes as inferred from hydrographic surveys, drifters and moorings, whilst section 3 covers the assumptions and processing used in inferring the current and eddy field from SeaWiFS data. Section 4 shows the results from analysis of more than 5 years of SeaWiFS data, linking/contrasting the results with the literature discussed before. Section 5 then summarises the results gained from this study using SeaWiFS data. 


\section{Background circulation}

The historical view of flow in the western Indian Ocean (Fig. la) involved the South Equatorial Current (SEC) at $15^{\circ} \mathrm{S}$ branching on reaching Madagascar, with $\sim 30 \mathrm{~Sv}$ flowing northward around the top of Madagascar and $20 \mathrm{~Sv}$ flowing south (Swallow et al., 1988). This latter flow, on reaching the Cape St. Marie at the southern point of the island, was then believed to head west to the east coast of the African mainland. There it joined up with the Mozambique Current, which originated from that portion of the North Madagascar Current (NMC) diverted southward, to form the Agulhas Current. Based on a number of hydrographic cruises, Sætre and Jorge da Silva (1984) suggest that the surface circulation varied seasonally, with a large $(400 \mathrm{~km})$ anticyclonic gyre dominating the southern Mozambique Channel during the austral summer, but a number of smaller features present in winter.

However more recent surveys have portrayed a very different pattern, with much more variability in the flow fields (Fig. 1b). The variability is apparent in altimetric analyses of sea surface height (e.g. Fu et al., 1988; Heywood and Somayajulu, 1997). The present picture for the flow in the Mozambique Channel no longer involves a steady current, but a train of anticyclonic eddies heading southward. These may be preformed eddies from the NMC moving over the confines of the Davie Ridge (depth $2500 \mathrm{~m}$, width 300 $\mathrm{km}$ ), but Ridderinkhof and de Ruijter (2003) suggest the eddies are generated in situ by the pinching off of the instabilities of an eastward current that penetrates across the Davie Ridge. Their analysis of mooring data across that choke point showed 4 or 5 'events' per year, corresponding to the progression/formation of a southward moving anticyclonic eddy.

These eddies tend to keep to the African coast, which produces the appearance of a semi-permanent poleward-flowing Mozambique Current. The mid-channel islands of Bassas da India and Île Europa (see Fig. 2) help restrict the route taken by these features. South of those islands there is less topographic constraint. A number of hydrographic surveys have come across anticyclonic features in this region, with diameters of the order of $200 \mathrm{~km}$ (de Ruijter et al., 2002). Southward coastal flow at $25^{\circ} \mathrm{S}$ often leads to the formation of a cyclonic lee eddy in the Delagoa Bight (Lutjeharms and Jorge da Silva, 1988).

The modern view on the fate of the East Madagascar Current has changed from a straight zonal flow towards the African coast to a number of diverse paths, each of which may only exist intermittently (Fig. 1b). From analysis of drifter data and thermal imagery from AVHRR, Lutjeharms (1 988a,b) was among the first to propound the existence of a retroflection of the East Madagascar Current akin to the behaviour noted for the Agulhas Current. By analogy with its southern counterpart it has been conjectured that the East Madagascar Retroflection sheds anticyclonic eddies, which could then migrate westwards. Tomczak and Godfrey (1994) and di Marco et al. (2002) suggest that often the EMC curves northwest after rounding Cape St. Marie, and then subsequently turns anticyclonically to head southwestwards towards the African mainland.

It is probable that the bathymetry has a key rôle in the behaviour of the current (lack of in situ observations makes it difficult to make definitive statements in terms of the depth penetration of the currents). A substantial ridge extends southwards from Madagascar, such that depths on the ridge are only $\sim 1000 \mathrm{~m}$, whereas the values a few hundred kilometres further west are $\sim 5000 \mathrm{~m}$. A local rise (to within $500 \mathrm{~m}$ of the sea surface) also exists at $45.8^{\circ} \mathrm{E}, 27.2^{\circ} \mathrm{S}$, which could well inhibit switching of the current between the eastern and northern sides of this mound.

Studies of drifter trajectories (Lutjeharms et al., 1981, Lutjeharms, 1988a) emphasise the great variability, with occasional buoys heading directly westwards from the EMC, others undergoing one or more anticyclonic loops to the south of Madagascar, and others returning to the east. Drifters have also often indicated a large cyclonic eddy beyond the end of the channel, typically centred around $38^{\circ} \mathrm{E}, 29^{\circ} \mathrm{S}$ (Gründlingh, 1977; Lutjeharms et al., 1981; Gründlingh et al., 1991)

As well as being a key physical control on the dynamics of the Agulhas Current system, the flow regime discussed plays an important part in the upwelling of deep nutrient-rich waters and the consequent encouragement of phytoplankton growth. Most coastal areas have higher nutrient content (and thus higher primary productivity) than the deep regions, because of the added contributions from riverine outflow. However, in certain areas, upwelling of deeper nutrient-rich water can lead to enhanced phytoplankton growth over a large expanse. This may result from wind-induced upwelling, but in the 
absence of such, can be caused by along-shore currents and changes in topography (Gill and Schumann, 1979), as has been noted for both the Natal Bight (Lutjeharms et al., 2000a) and south of Madagascar (Lutjeharms and Machu, 2000). Figure 3 shows the mean distributions of chlorophyll for four months of the year, obtained from SeaWiFS data. These show that the enhanced chlorophyll region around Madagascar begins some way up the east coast, although this feature is more prominent to the south of the island. Along the western edge of the southern Mozambique Channel, the strongest upwelling (and thus phytoplankton growth) occur at the Natal Bight $\left(29^{\circ}-30^{\circ} \mathrm{S}\right)$, the Delagoa Bight $\left(25-26^{\circ} \mathrm{S}\right)$ and the Banco de Sofala, a shallow shelf between 20 and $23^{\circ} \mathrm{S}$ along the Mozambican coast. For many of the months there appears to be a tongue of high chlorophyll concentration (CC) water dragged out from southern Madagascar towards the west-southwest. This can be seen in some individual scenes, but often snapshots show this tongue has separated out into individual patches of chlorophyll. There is no clear tongue of high CC water in the mean climatologies for December and January (austral summer). Figure 3 also reveals the seasonal signal of the deep ocean, with an early 'spring bloom' in July, as the temperatures start to increase once more. Longhurst (2001) also noted enhanced growth at these latitudes in March and April, as a result of the deep mixing induced by increased trade winds; however, this secondary bloom is confined to the region east of Madagascar.

\section{Analysis of SeaWiFS data}

The SeaWiFS instrument was launched on 1st August 1997, and the first data collected on 4th September. Since then, there has been almost uninterrupted coverage. We used daily global files of chlorophyll data, as provided by GSFC DAAC on a $9 \mathrm{~km}$ grid. The results presented herein use version 4 of the data, as released in July 2002.

Even in the absence of cloud cover, SeaWiFS cannot give complete global coverage in one day. Thus although one-day images are useful for examining individual features, we have routinely composited the data into successive 6-day periods (hexads). The choice of six days for averaging is a compromise between achieving nearly complete spatial coverage, but without features being blurred excessively by their movement during the compositing interval. [Lutjeharms et al. (1981) and de Ruijter et al. (2002) note rotation periods for eddies in the range 4 to 10 days.] Most of the time that interval is sufficient to give nearly complete coverage of the southern Mozambique Channel, however there are often periods of few observations between mid November and the end of January (see Fig. 4).

The recovered $\mathrm{CC}$ covers a wide dynamic range, from less than $0.04 \mathrm{mg} \mathrm{m}^{-3}$ to more than $1.4 \mathrm{mg} \mathrm{m}^{-3}$, and their relative frequency of occurrence conforms fairly well to the expected lognormal distribution (Campbell, 1995). Our interest is not in the absolute CC per se, but in the use of phytoplankton as a tracer for delineating the boundary between different water masses. Consequently, we use $\log _{10}\left(\mathrm{CC}\right.$ in $\left.\mathrm{mg} \mathrm{m}^{-3}\right)$ as our 'observable' and perform averaging (whether in time-compositing or in spatial smoothing) in this transformed space.

In using $\mathrm{CC}$ as a marker for different water masses, we note that the EMC itself is marked by low chlorophyll, possibly due to low levels of nutrients (nutrient levels to the east of Madagascar are low, but there is a paucity of data; see Conkright et al., 1998). However, on its western side the EMC borders on the region of near-permanent upwelling, and may entrain some of this high $\mathrm{CC}$ water. Of course $\mathrm{CC}$ is not a conservative tracer, so as well as the signal of a parcel of water being diluted by mixing, there will also be biological growth, or rather mortality, as the water carrying the phytoplankton is cut off from any further source of nutrient supply. The clearest feature for remote identification is thus not the core of the EMC but its sharp border with other water masses. The same is true for eddies in the Mozambique Channel. Although McGillicuddy et al. (1998) have suggested that cyclonic eddies can generate a chlorophyll signal of their own through enhanced central upwelling, it is more common for the eddies in the Mozambique Channel to be imaged through the trail of higher CC coastal water that they have swept around them.

Therefore this study is not overly concerned with the absolute values of the chlorophyll concentration, but rather their ability to highlight boundaries indicative of a change in physical flow. The corollary is 
that the absence of a signal in ocean colour does not necessarily imply the absence of any strong flows, since an homogeneous background chlorophyll distribution will not delineate such physical features.

The overall stated accuracy goal for SeaWiFS-derived chlorophyll concentrations was $35 \%\left(1 \mathrm{~km}^{2}\right.$ pixels; Hooker and McClain, 2000). We are using the $9 \mathrm{~km} \times$ x $9 \mathrm{~km}$ version 4 product, and the compositing procedure will typically make use of 3 or 4 independent views (provided it is not a cloudy period). We do not know the absolute accuracy of our derived fields (as this will depend upon assumptions of the scale length and period for the various causes of error). However, coherent features may be found corresponding to a change in $\log _{10}(\mathrm{CC})$ of 0.04 , equivalent to a $\mathrm{CC}$ change of $10 \%$. A logarithmic change of 0.1 corresponds to an increase of CC by $26 \%$, and the features shown within this paper all have a signature much greater than that. In fact, the examples discussed are a selection biased towards those that are in cloud-free periods, that have a strong ocean colour signature, and whose interpretation is not complicated by the presence of other features. For the various types of behaviour discussed, we show a number of examples to illustrate that they are not 'one offs', and to portray the variety within the -5 year time series. Note that the features cannot be atmospheric artefacts, because atmospheric phenomena would have a much larger scale (- $1000 \mathrm{~km}$ across) and would not be linked to the bathymetry.

\section{Results}

Having divided the more than 5 year dataset into successive hexads, we have over 330 composite images of the area to examine. These contain a great many features likely to be associated with eddy activity. Within this written paper we have focussed on a number of frequently occurring features, which we illustrate using examples where the contrast in observed chlorophyll is strong (change in $\log _{10}(\mathrm{CC})>$ 0.1 ), and where the feature under consideration is not too affected by other aspects of the flow in the region. The full dataset is provided as an animation file. To overcome some of the sharper temporal changes in chlorophyll, and especially the occasional patches of cloud, the images in the animation (and some of those in the written paper) have had further spatial and temporal smoothing applied. (We used a simple 3-point [0.25 0.50 .25 ] smoothing filter in both spatial dimensions and in time.) The animation makes it easier to follow the evolution of some events, which are otherwise portrayed as a series of staccato scenes.

We now focus on selected features in turn, and discuss them with respect to other observations, such as those from hydrographic surveys and satellite sea surface temperature (SST) measurements.

\subsection{Eddies on the western side of the channel}

A train of low chlorophyll concentration (CC) features is found to progress along the western edge of the Mozambique Channel. The movement is illustrated in two series of composites (Fig. 5).

The top row contains images from March-May 1998, showing a $250 \mathrm{~km}$ wide low CC feature centred at $38^{\circ} \mathrm{E}, 23^{\circ} \mathrm{S}$, with another one entering at the top of the picture. Between them appears to be a tongue of high CC water pulled out to about $500 \mathrm{~km}$ from the coast. Figure $5 \mathrm{~b}$ shows the scene twelve days later, with both low $\mathrm{CC}$ features moving south. Note the increase in area for which $\log _{10}(\mathrm{CC})<-1$ should not necessarily be interpreted as an increase in the size of the feature. A number of other processes (phytoplankton mortality, predation and/or vertical mixing in the water column) can also explain the observed change in size. Figure $5 \mathrm{c}$ shows the end of the sequence (48 days after Fig. $5 \mathrm{a}$ ), with the eddy previously centred near $20^{\circ} \mathrm{S}$ now at $23.5 \mathrm{~S}$, with its anticyclonic nature clearly indicated by the higher $\mathrm{CC}$ waters beginning to wrap around it there. There are also suggestions of a resumption of the tongue of extruded coastal water at $22^{\circ} \mathrm{S}$. Although the three images shown imply a mean southward velocity for the eddy of $7 \mathrm{~km} \mathrm{day}^{-1}$, the animation reveals that the movement is far from steady. The derived propagation rate is consistent with other estimates (de Ruijter et al., 2002; Schouten et al., 2003; Gründlingh, 1995), although the last author was interpreting his results as cyclonic rather than anticyclonic eddies. 
The second series of composites covers the period March-May 2000. In the first (Fig. 5d) a low CC feature is located at $24^{\circ} \mathrm{S}$, with the pattern of chlorophyll again indicative of advection around an anticyclonic eddy. Twelve days later (Fig. 5e) the feature lies $0.5^{\circ}$ further south, but has lost some of the contrast with neighbouring water. In the third image (Fig. 5f), the eddy is now centred at $35^{\circ} \mathrm{E}, 27^{\circ} \mathrm{S}$ (this is more easily followed in the animation). During this time a tongue of higher $\mathrm{CC}$ water remains intact at $21^{\circ} \mathrm{S}$. It is tempting to speculate that there is a preferred location for this tongue, due to the southward passage of eddies being held up by the constriction between the African mainland and the small islands of Bassas da India and Île Europa in mid-channel. However, Figs. 5g \& i show that this tongue can be stable as far south as $23^{\circ} \mathrm{S}$.

The Delagoa Bight is the shallow shelf centred on $34^{\circ} \mathrm{E}, 26^{\circ} \mathrm{S}$, and is known as a location for the formation of lee eddies (Lutjeharms and Jorge da Silva, 1988). As the shelf is particularly wide, with nutrients supplied by both the Limpopo and coastal upwelling, the whole of the region is marked by high levels of chlorophyll. However, in Figs. $5 \mathrm{~b}, \mathrm{~g} \& \mathrm{~h}$ a thin southbound strip of high CC water roughly follows the $800 \mathrm{~m}$ isobath. These observations are similar to those of Lutjeharms and Jorge da Silva (1988) using thermal imagery, who also noted a northward flow up the western edge of the bight. They recorded the frequent occurrences of this lee eddy, $-180 \mathrm{~km}$ in diameter, but noted that it was not a permanent feature, as the warm southward flow sometimes lay much further west, with small-scale instabilities on its landward side. In a pioneering attempt at using ocean colour data to study the flow in this region, Gründlingh et al. (1989) found a suggestion of anticyclonic circulation, with a tight coastal flow towards the south. However, chlorophyll-rich water advected by along-shore flows is hard to distinguish from variable upwelling and consequent phytoplankton growth due to changing winds. Interestingly, Figs. $5 \mathrm{~d} \&$ e show the apparent generation of a cyclonic flow at $35.5^{\circ} \mathrm{E}, 25.5^{\circ} \mathrm{S}$ to the east of the shelf region. This is presumably generated by the southward passage of the offshore anticyclonic feature at $38^{\circ} \mathrm{E}, 24^{\circ} \mathrm{S}$, and is a reminder that a continuous Mozambique Current is not necessary for the growth of lee eddies in this region. A number of other examples can be seen in the animation sequence.

\subsection{Eddies on the eastern side of the channel}

On the eastern side of the Mozambique Channel, a number of cyclonic features can be found level with the southern tip of Madagascar (Fig. 6). These are not permanent features, as might be expected for a leetype eddy, but occur intermittently. The series in the top row (Figs. 6a-d) spanning a period of 24 days, shows how quickly the entrainment pattern is developed for the eddy at $43^{\circ} \mathrm{E}, 23^{\circ} \mathrm{S}$, with a second cyclonic pattern appearing at the end of the sequence a little further southeast. The second row of examples (Fig. 6e-h) illustrates that these eddies may be centred at a number of locations, although just west of Cape St. Marie does seem to be a good location for creating a strong contrast between entrained chlorophyll-rich waters and the core of the eddy. Thus, although many of the clearest examples may suggest the formation of a lee eddy in the shelter of Madagascar, the observations are also consistent with a pre-formed cyclonic eddy drifting south- or southeastward into the region, and only becoming apparent as it draws high productivity coastal waters around it. This is especially true for the sequence shown in Fig. 6a-d where the first eddy to be imaged was significantly north of Cape St. Marie.

One particular feature we have observed in two other ways. This is the cyclonic eddy occurring in mid November 2001 (Fig. 7). A swath of temperature measurements recorded by ATSR-2 (Fig. 7a) shows the same location for the feature noted in the chlorophyll pattern (Fig. 7b). These images (and preceding ones) were used to direct the path of the research vessel $R R S$ Darwin, enabling us to improve its chances of surveying an eddy in this region. XBTs were deployed every $0.25^{\circ}$ along the track between $21^{\circ} \mathrm{S}$ and $27^{\circ} \mathrm{S}$. The derived section (Fig. 8) shows doming of the upper isotherms around $26^{\circ} \mathrm{S}$ as the ship's track crosses the edge of the eddy. No concurrent salinity data are available, but if it is assumed that the isopycnals are raised in a similar manner to the isotherms, this would be consistent with a section across the edge of a cyclonic eddy $250 \mathrm{~km}$ in diameter, but with only the westward flow near $27^{\circ} \mathrm{S}$ having a clear penetration below $200 \mathrm{~m}$. The XBT section was 2-3 days after the images shown in Fig. 7; although the eddy may have moved a little, it is likely that the section was still well to the west of the centre of the feature. Unfortunately there was no time available to continue this survey, so the section in Fig. 8 
probably underestimates the amount the isotherms are raised. [ Sections directly across mid-channel cyclones reveal raised isotherms throughout most of the top 1000m (Gründlingh, 1977, 1985).]

\subsection{Westward propagation of features}

The large cyclonic eddies imaged just to the southwest of Madagascar do not remain there permanently. After initially wrapping high CC waters around the periphery, the whole feature becomes marked by enhanced chlorophyll levels. In several cases (Figs. 9a-i, 9j-o) there appear to be coherent enhanced chlorophyll features propagating in a westerly or west-southwesterly direction. Both series show every other rather than consecutive hexads, so the left-hand column covers a period of 102 days. One feature appears in Fig. 9a at $42^{\circ} \mathrm{E}, 27^{\circ} \mathrm{S}$ and proceeds in WSW direction towards Durban, reaching $35^{\circ} \mathrm{E}, 29^{\circ} \mathrm{S}$ in Fig. 9i. This corresponds to an average propagation rate of $7.5 \mathrm{~km} \mathrm{day}^{-1}$, although the inferred speed in the centre of the channel (between Figs. 9c \& 9f) exceeds $10 \mathrm{~km} \mathrm{day}^{-1}$. A second cyclonic feature can be seen at $44^{\circ} \mathrm{E}, 26^{\circ} \mathrm{S}$ in Fig. 9c, which subsequently moves west-southwestwards too. Its propagation rate is very similar to that of its predecessor, including a substantial acceleration across the mid-channel between Figs $9 \mathrm{~h} \& \mathrm{i}$. However, it is difficult to trace the eddy in earlier images in order to address the question of its origin.

The second series (Figs. 9j-o) shows the imaging of a cyclonic eddy which heads due westwards at $25^{\circ} \mathrm{S}$ from $41.5 \mathrm{E}$ in Fig. $9 \mathrm{k}$ to $37.5^{\circ} \mathrm{E}$ in Fig. $9 \mathrm{o}$. The average propagation speed over this interval is $7 \mathrm{~km}^{-} \mathrm{day}^{-}$ 1 , but with a greater rate in mid-channel (between Figs. $9 \mathrm{~m} \& 9 \mathrm{o}$ ) than earlier in the sequence. In an altimetric analysis of this region, Gründlingh (1995) found cyclonic eddies propagating westsouthwestwards at 6-7 km day ${ }^{-1}$. Using contemporaneous TOPEX/Poseidon sea surface height anomaly data, we have confirmed that the three high CC features marked in Figs. 9a-o do correspond to cyclonic eddies.

We have constructed entire-mission Hovmöller diagrams along these two propagation routes. A section of the time series for the west-southwesterly route is shown in Fig. 10a. It is strongly dominated by the annual changes in $\mathrm{CC}$, but a number of westward-moving features can be discerned on the eastern side of the section. The large-scale secular variation cannot be removed by simply subtracting the spatial mean for each hexad, because in the first few calendar months the general levels of CC are much higher off Madagascar than off Durban. Instead, we adopt the 'local anomaly' filter (Quartly et al. 2003), whereby the value at a location along track is referenced to the average over some larger segment (here $200 \mathrm{~km}$ ) centred on that point. Each hexad is treated separately, so there is no filtering in time; however the resultant filtered field (Fig. 10b) clearly shows a much larger number of westward-moving features.

From examination of Fig. 10b alone, it might be argued that the moving features are Rossby waves, as they have an ocean colour signature, with results for these latitudes to the east of Madagascar showing increases in CC coinciding exactly with decreases in sea surface height (Quartly et al., 2003). However, our (limited) hydrographic observations of cyclonic eddies to the immediate southwest of Madagascar, and the fact that these features maintain a roughly circular appearance (Fig. 9) rather than forming a wavefront, convince us that what we are observing are the movement of eddies carrying water in a westerly or WSW direction. This interpretation ties in well with the various observations of cyclonic eddies in this region by altimetry (Gründlingh, 1995), hydrographic surveys (Gründlingh et al., 1991) and the mapping of drifter trajectories (Lutjeharms et al., 1981; Gründlingh, 1977).

The Hovmöller analysis helps demonstrate the fairly steady movement of some features, but not all cyclonic features follow the same route (as exemplified by the two sequences Fig. 9); and even if there were a clear preferred path, there are other factors modulating the ocean colour signal as well as other features propagating into the region along the western edge of the Mozambique Channel. The actual path adopted by a given eddy will be affected by its baroclinicty (and thus response to bathymetry, see Fig.2), as well as interaction with other eddies (de Ruijter et al., 2003). 


\subsection{Observations of East Madagascar Retroflection}

Lastly we focus on the waters of the East Madagascar Current itself, comparing the observations with the various ideas illustrated in Fig. lb concerning its behaviour. Note that low levels of chlorophyll mark the EMC, but its track is delimited by the border it has with entrained coastal waters.

Figure 9n-r show chlorophyll patterns apparently indicative of a retroflection with the EMC turning anticyclonically to the south of Madagascar, before eventually heading east or northeastward. Although there are a number of other examples in our series of 330 images (see the animation) there is no sequence in which it is clear that an anticyclonic eddy is being pinched off and heading west. Such behaviour might be expected by analogy with the Agulhas retroflection. In an earlier work (Quartly and Srokosz, 2002) we looked at SST data from a passive microwave sensor which overcomes the problems of cloud cover; our records of 'warm anomalies' typical of anticyclonic eddies tended to show a southwestward progression. However, that analysis did not directly observe the generation of an anticyclonic eddy by the retroflection.

On a number of occasions (e.g. Figs. 9i,j) the core of the EMC appears to continue in a WSW direction without any retroflection. di Marco et al. (2000) suggest that there might be a seasonality in the behaviour of the EMC despite Schott et al. (1988) and Lutjeharms et al. (2000b) finding little seasonality in the flow of the EMC. There is however a seasonal cycle in the wind stress field over the Indian Ocean. Quartly and Srokosz (1993) had noted a seasonal variation in the location of the Agulhas Retroflection (further west in austral winter, further south in summer), which Ffield et al. (1998) attributed to the annual cycle in wind stress over the southern Indian Ocean. Similarly, Heywood and Somayajulu (1997) argue that, in winter, the stronger trade winds over the South Equatorial Current increase its transport and lead to higher levels of eddy kinetic energy in the region. di Marco et al. (2000) suggest that this change leads to the EMC tending to follow the westward path in winter, but adopting the more northerly path in summer (cf. Fig. 1 b). Our analysis of SeaWiFS data does not provide any support for this northerly path for the current, nor does it show any clear seasonal behaviour.

\section{Discussion and conclusions}

SeaWiFS data provide a valuable resource in the imaging of physical processes within the southern Mozambique Channel. Whilst chlorophyll concentration (CC) may be changed by local biological processes (growth/mortality/predation), as well as mixing to below the effective optical depth of the satellite sensor, it has proven to be a useful indicator of coherent bodies of water. This has enabled us to distinguish eddies or currents where they are marked by a strong $\mathrm{CC}$ front. Clearly there may be circulatory features that are poorly imaged, if at all, due to the absence of a strong contrast in water properties. The same is true for the use of infra-red sensors, when there may be no horizontal thermal gradient at the surface. Several authors have studied features in this region by observing their thermal signature. However, atmosphere-ocean heat fluxes can be large here, leading to the erosion of a signal in surface temperature. Lutjeharms and Jorge da Silva (1988) note the Delagoa Bight eddy to be present in only $10 \%$ of clear SST images, whereas hydrographic surveys reveal it to be nearly always present, although with a clearer signal at 100m depth than at the surface. Gründlingh (1995) also notes that many of cyclonic eddies lack the expected 'cold core' signal at the surface. As CC provides a depth-integrated indicator of the water mass, it tends to be more resilient to change. Either way, maps of SST and CC both selectively reveal features, and cannot be assumed to record all of them. These limitations aside, the satellite data significantly enhance our understanding of the flow in the southern Mozambique Channel.

Large (200 km diameter) chlorophyll features are noted tracking down the western edge of the channel. The patterns of chlorophyll-rich water advected around them imply an anticyclonic circulation. Anticyclonic eddies have been noted in this region from altimetry (Schouten et al., 2003), occasional ship surveys (de Ruijter et al., 2002) and found in model simulations (Biastoch and Krauss, 1999; see also the Southampton Oceanography Centre's OCCAM model results - animations available from http://www.soc.soton.ac.uk/JRD/OCCAM/agulhas.html). Their southward journey is irregular, and they do not follow exactly the same route as one another. The sequence illustrated in Fig. 5a-c show a 48-day 
interval between eddies, and we find typically 5 or 6 events per year, although the identification of features is somewhat subjective during the spring bloom periods. This figure is consistent with the frequency of 'events' detected by the moorings along the Davie Ridge (Ridderinkhof and de Ruijter, 2003) and altimetric analysis (Schouten et al., 2003). Ridderinkhof and de Ruijter (2003) estimate the water transported by these eddies to be equivalent to a mean flow through the channel of $15 \mathrm{~Sv}$.

Present research no longer supports the idea of a permanent Mozambique Current. However the Delagoa Bight eddy (Lutjeharms and Jorge da Silva, 1988) is frequently observed in the SeaWiFS data, and may be enhanced (either in actual flow or in visual contrast) by the passage of the large anticyclonic eddies to its seaward side.

Anticyclonic East Madagascar rings were expected to be evident on the eastern side of the channel; however, no clear shedding events were observed. di Marco et al. (2002) also state that the many eddies in the Mozambique Channel are 'apparently not caused by shedding at the EMC retroflection'. Instead the main features we noted in this region were cyclonic eddies $(250 \mathrm{~km}$ in diameter $)$ that were visible in the lee of the southern tip of Madagascar. Our SeaWiFS analysis is complemented by the XBT section from RRS Darwin (Fig. 8) and the WOCE 14 section (di Marco et al., 2002). These eddies may have been generated in situ by the flow around Cape St. Marie. However the intermittency of this flow and the observations of eddy activity more than $100 \mathrm{~km}$ further north (Fig. 7a-d) imply that it is likely that many of these features may have formed earlier and only became manifest upon impinging the west of Madagascar and then advecting coastal waters around them. Indeed it is likely that drifters caught by such an eddy would give the impression of a northwesterly route for the EMC upon rounding Cape St. Marie. di Marco et al. (2002) note that the 'northward loop is often displaced to the west away from the Madagascar coast'.

These large cyclonic eddies appear to migrate roughly west-southwestwards to the African mainland; such a propagation route has also been noted using altimeter data (Gründlingh, 1995). Several hydrographic surveys have noted large cyclonic eddies in the southern reaches of the Mozambique Channel, and even on the edge of the Agulhas Current off Durban (Gründlingh and Pearce, 1984). Our analysis shows these to lie on a fairly common path for eddy propagation, and this obviates the need for an eddy generation mechanism on the Mozambique Ridge (Gründlingh, 1987). Model results do not appear to capture this aspect of the flow very clearly (Biastoch and Krauss, 1999; OCCAM, http://www.soc.soton.ac.uk/JRD/OCCAM/agulhas.html).

A number of images did give a clear picture of a retroflecting East Madagascar Current (Figs. 9n-r). However at other times a tongue of low CC water (typical of the EMC) continued beyond the Madagascar Ridge in a west-southwesterly direction. Thus it is clear that a multiplicity of flow regimes exist in this region, which need to be investigated further.

\section{Acknowledgements}

The authors would like to thank the SeaWiFS Project (Code 970.2) and the Distributed Active Archive Center (Code 902) at the Goddard Space Flight Center (GSFC), Greenbelt, MD 20771, for the production and distribution of these data, respectively. These activities are sponsored by NASA's Mission to Planet Earth Program. Near real-time SeaWiFS data at the time of the RRS Darwin cruise were obtained from GSFC with the help of Gene Feldman, and the ATSR-2 data from ESA, all through the great work of our data managers, Lisa Redbourn-Marsh and Cristina Peckett. We appreciate the effort of Robin Pascal and the crew of RRS Darwin in using spare time at sea to chase eddies for us. The quality of the attendant animation was greatly improved by the assistance of Mike Conquer. 


\section{References}

Biastoch, A. and Krauss, W. 1999 The role of mesoscale eddies in the source regions of the Agulhas Current. Journal of Physical Oceanography, 29, 2303-2317.

Campbell, J. W., 1995: The lognormal distribution as a model for bio-optical variability in the sea. Journal of Geophysical Research, 100, 13237-13254.

Conkright, M. E., O'Brien, T. D., Levitus, S., Boyer, T. P., Stephens, C. and Antonov, J. I. 1998 World Ocean Atlas 1998. Volume 12: Nutrients and chlorophyll of the Indian Ocean, NOAA Atlas, NESDIS No. 38.

de Ruijter, W. P. M., Ridderinkhof, H., Lutjeharms, J. R. E., Schouten, M. W. and Veth, C. 2002: Observations of the flow in the Mozambique Channel. Geophysical Research Letters, 29 (10), 140:1-4. DOI 10.1029/2001GL013714.

de Ruijter, W. P. M., van Aken, H. M., Beier, E. J., Lutjeharms, J. R. E., Matano, R. P. and Schouten, M. W. 2003: Eddies and dipoles around South Madagascar: formation, pathways and large-scale impact. (submitted to Deep-Sea Research)

di Marco, S. F., Chapman, P. and Nowlin, W. D. 2000 Satellite observations of upwelling on the continental shelf south of Madagascar. Geophysical Research Letters, 27, 3965-3968.

di Marco, S. F., Chapman, P., Nowlin, W. D., Hacker, P., Donohue, K., Luther, M., Johnson, G. C. and Toole, J. 2002 Volume transport and property distributions of the Mozambique Channel. Deep-Sea Research II, 49, 1481-1511.

Ffield, A., Toole, J. and Wilson, D. 1997 Seasonal circulation in the South Indian Ocean, Geophysical Research Letters, 24, 2773-2776.

Fu, L.-L., Chelton, D. B. and Zlotnicki, V. 1988 Satellite altimetry: Observing ocean variability from space. Oceanography, 1, 4-11,58.

Gill, A. E. and Schumann, E. 1-1. 1979 Topographically induced changes in the structure of an inertial jet: application to the Agulhas Current, Journal of Physical Oceanography, 9, 975-991.

Gründlingh, M. L., 1977: Drift observations from Nimbus VI satellite-tracked buoys in the southwestern Indian Ocean. Deep-Sea Research, 24, 903-913.

Gründlingh, M. L., 1985: An intense cyclonic eddy east of the Mozambique Ridge. Journal of Geophysical Research, 90, 7163-7167.

Gründlingh, M. L., 1987 Cyclogenesis in the Mozambique Ridge Current. Deep-Sea Research, 34, 89103.

Gründlingh, M. L., 1995 Tracking eddies in the southeast Atlantic and southwest Indian oceans with TOPEX/POSEIDON. Journal of Geophysical Research, 100, 2497724986.

Gründlingh, M. L. and Pearce, A. F. 1984: Large vortices in the northern Agulhas Current. Deep-Sea Research, 31, 1149-1156.

Gründlingh, M. L., Carter, R. A. and Stanton, R. C. 1991 Circulation and water properties of the southwest Indian Ocean, spring 1987. Progress in Oceanography, 28, 305342.

Gründlingh, M. L., Slinger, D. H. and Agenbag, J. J. 1989 The usefulness of Nimbus CZCS imagery in the south-western Indian Ocean. South African Journal of Marine Science, 8, 261-269.

Heywood, K. J. and Somayajulu, Y. K. 1997 Eddy activity in the south Indian Ocean from ERS- I altimetry. Proceedings of 3rd ERS Symposium - Space at the service of our environment, Florence, Italy, ESA SP-414, 1479-1483.

Hooker, S. B. and McClain., C. R. 2000 The calibration and validation of SeaWiFS data. Progress in Oceanography, 45, 427-465. 
Longhurst, A., 2001 A major seasonal phytoplankton bloom in the Madagascar Basin. Deep-Sea Research I, 48, 2413-2422.

Lutjeharms, J. R. E. 1988a On the role of the East Madagascar Current as a source of the Agulhas Current. South African Journal of Science, 84, 236-238.

Lutjeharms, J. R. E. 1988b Remote sensing corroboration of retroflection of the East Madagascar Current. Deep-Sea Research, 35, 2045-2050.

Lutjeharms, J. R. E. and Jorge da Silva, A. 1988 The Delagoa Bight eddy. Deep-Sea Research, 35, 619634.

Lutjeharms, J. R. E. and Machu, E. 2000 An upwelling cell inshore of the East Madagascar Current. Deep-Sea Research, 47, 2405-2411.

Lutjeharms, J. R. E., Bang, N. D. and Duncan, C. P. 1981 Characteristics of the currents east and south of Madagascar. Deep-Sea Research, 28A, 879-899.

Lutjeharms, J. R. E., Cooper, J. and Roberts, M. 2000a Upwelling at the inshore edge of the Agulhas Current. Continental Shelf Research, 20, 737-761.

Lutjeharms, J. R. E., Wedepohi, P. M. and Meeuwis, J. M. 2000b On the surface drift of the East Madagascar and Mozambique Currents. South African Journal of Science, 96, 141-147.

McGillicuddy, D. J., Robinson, A. R., Siegel, D. A., Jannasch, H. W., Johnson, R., Dickey, T. D., McNeil, J., Michaels, A. F. and Knap, A. H. 1998 Influence of mesoscale eddies on new production in the Sargasso Sea. Nature, 394, 263-266.

Quartly, G. D. and Srokosz, M. A. 1993 Seasonal variations in the region of the Agulhas Retroflection: Studies with Geosat and FRAM. Journal of Physical Oceanography, 23, 2107-2124.

Quartly, G. D. and Srokosz, M. A. 2002 TMI observations of the Agulhas and Madagascar retroflections. Journal of Physical Oceanography, 32, 1585-1592

Quartly, G. D., Cipollini, P., Cromwell, D. and Challenor, P. G. 2003 Rossby waves: Synergy in action. Phil. Trans. Roy. Soc. Lond A, 361, 57-63

Ridderinkhof, H. and de Ruijter, W. P. M. 2003 Moored current observations in the Mozambique Channel. Deep Sea Research, Deep-Sea Research II, 50 (12-13), 1933-1955.

Sætre, R., and Jorge da Silva A. 1984 The circulation of the Mozambique Channel. Deep Sea Research, 31, 485-508.

Schott, F., Fieux, M., Kindle, J., Swallow, J. and R. Zantopp, 1988 Boundary currents east and north of Madagascar. 2. Direct measurements and model comparisons. Journal of Geophysical Research, 93, 4963-4974.

Schouten, M. W., de Ruijter, W. P. M., van Leeuwen, P. J. and Ridderinkhof, H. 2003, Eddies and variability in the Mozambique Channel Deep-Sea Research II, 50 (12-13), 1987-2003.

Stramma L. and Lutjeharms J. R. E. 1997 The flow field of the subtropical gyre of the South Indian Ocean. Journal of Geophysical Research, 102, 5513-5530.

Swallow, J., Fieux, M. and Schott, F. 1988: The boundary currents east and north of Madagascar 1. Geostrophic currents and transports. Journal of Geophysical Research, 93, 4951-4962.

Tomczak, M. and Godfrey, J. S. 1994: Regional oceanography: An introduction. Pergamon, 422 pp. 

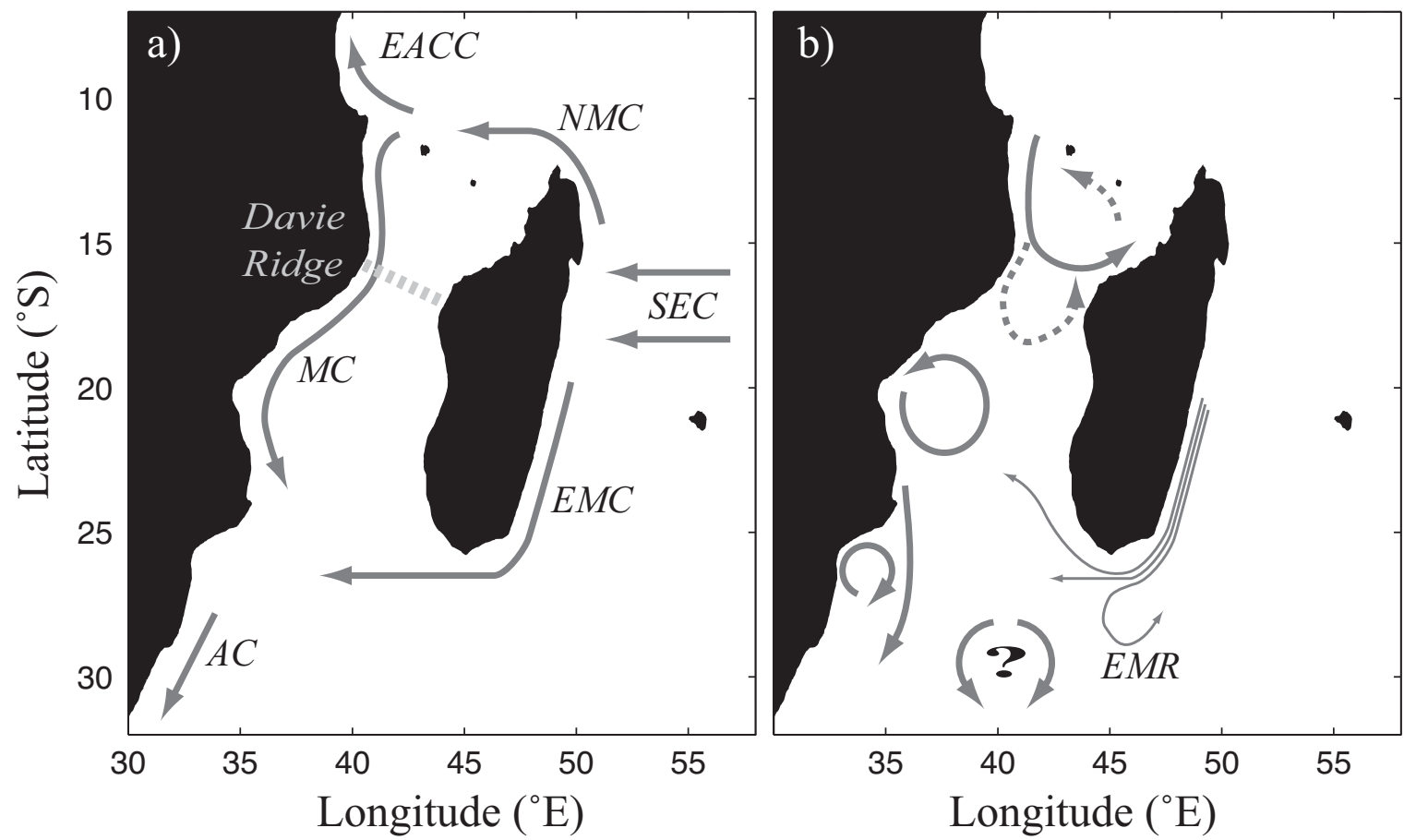

Figure 1. Schematic of circulation. a) Long-term mean flow derived from windforcing and mean water properties. b) Variability in features. SEC - South Equatorial Current, NMC - North Madagascar Current, EACC - East African Coastal Current, EMC - East Madagascar Current, MC - Mozambique Current, AC - Agulhas Current, EMR East Madagascar Retroflection.

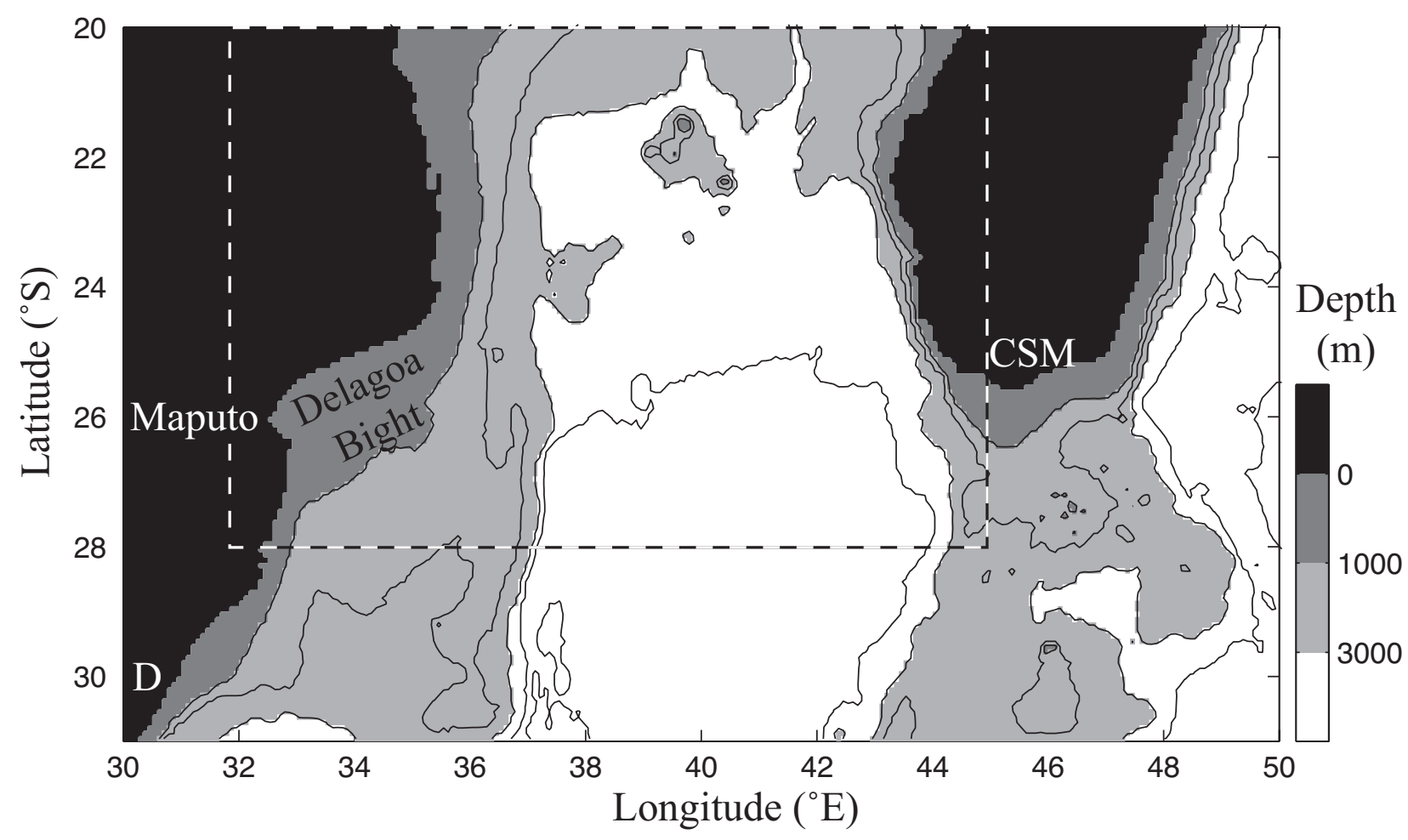

Figure 2. Bathymetry of the region of interest, with contours every $1000 \mathrm{~m}$. D Durban, CSM - Cape St. Marie (now known as Tanjana Vohimena). Note the southward extensions of the Mozambique Ridge (36E) and the Madagascar Ridge (45E) as well as the two small islands within the Mozambique Channel - Bassas da India $\left(39.5^{\circ} \mathrm{E}, 21.5^{\circ} \mathrm{S}\right)$ and Île Europa $\left(40.5^{\circ} \mathrm{E}, 22.5^{\circ} \mathrm{S}\right)$ - so small as to be effectively invisible in the plot, but situated at the top of the two rises that can be clearly seen. The boxed region delimits the 'southern Mozambique Channel' referred to in Fig. 4. 

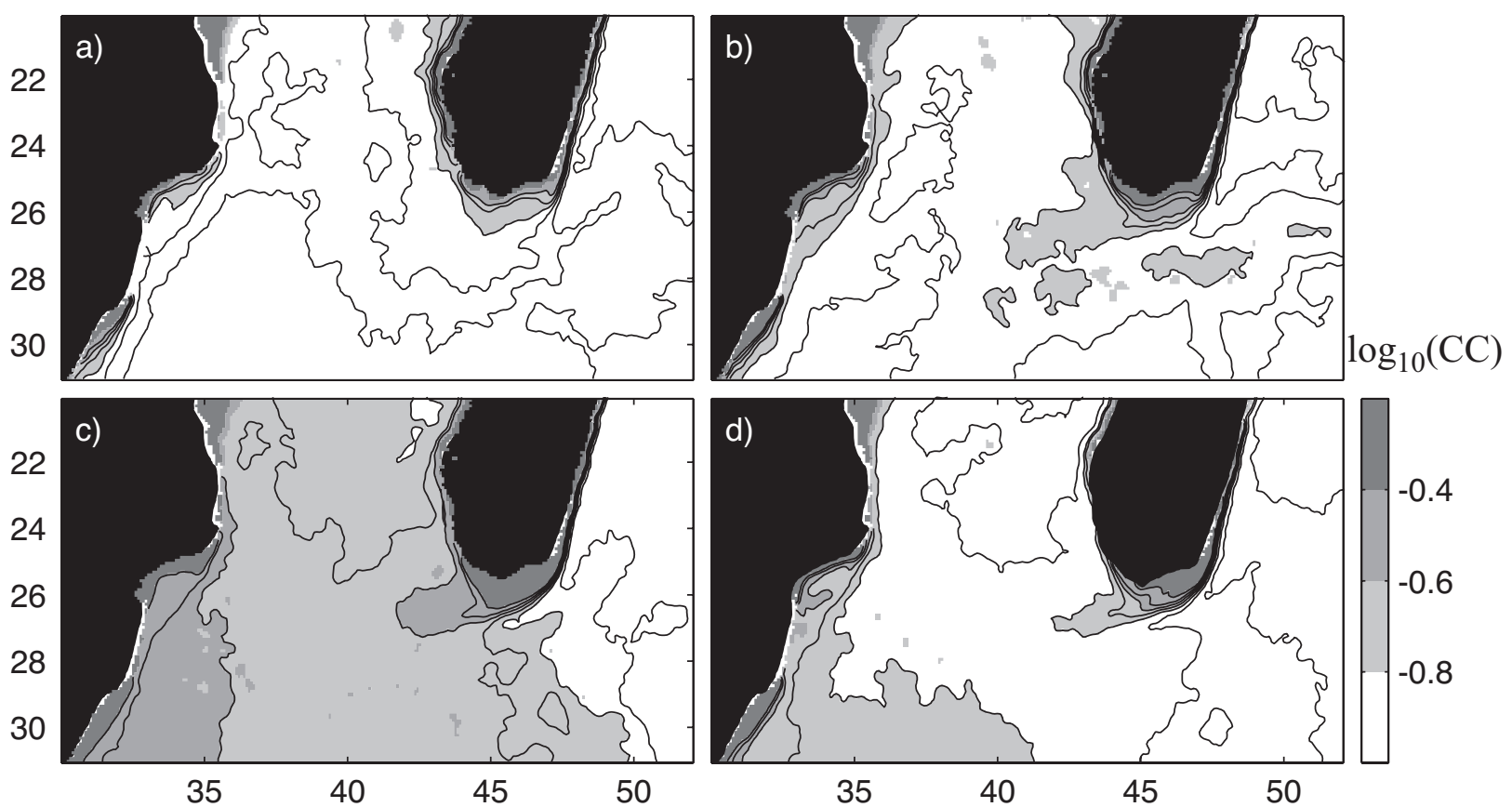

Figure 3. Seasonal cycle of chlorophyll concentration, displayed by monthly mean values of $\log _{10}(\mathrm{CC}$ in mg m3) for a) January, b) April, c) July, d) October. The SeaWiFS data are averaged over 5 years, with contours for every step of 0.1 in $\log _{10}(\mathrm{CC})$.

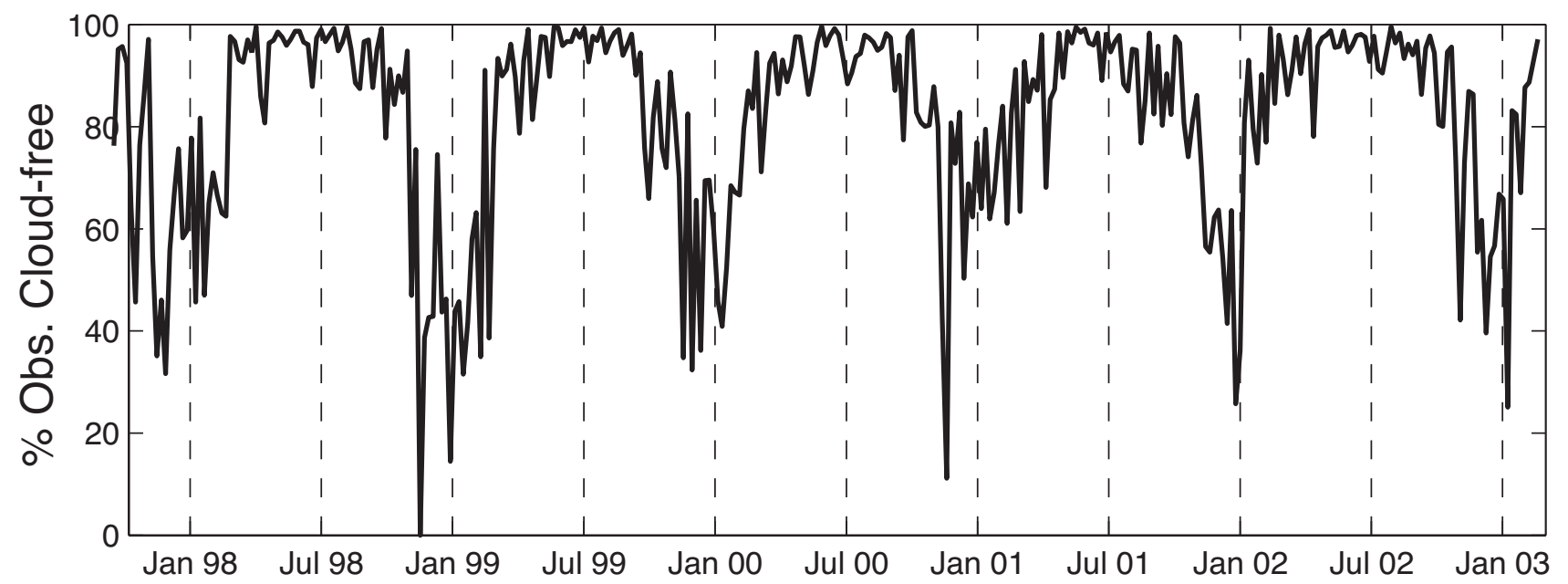

Figure 4. Percentage of good observations for each hexad. Low values indicate persistent cloud cover. Analysis is of southern Mozambique Channel region (box indicated in Fig.2) 

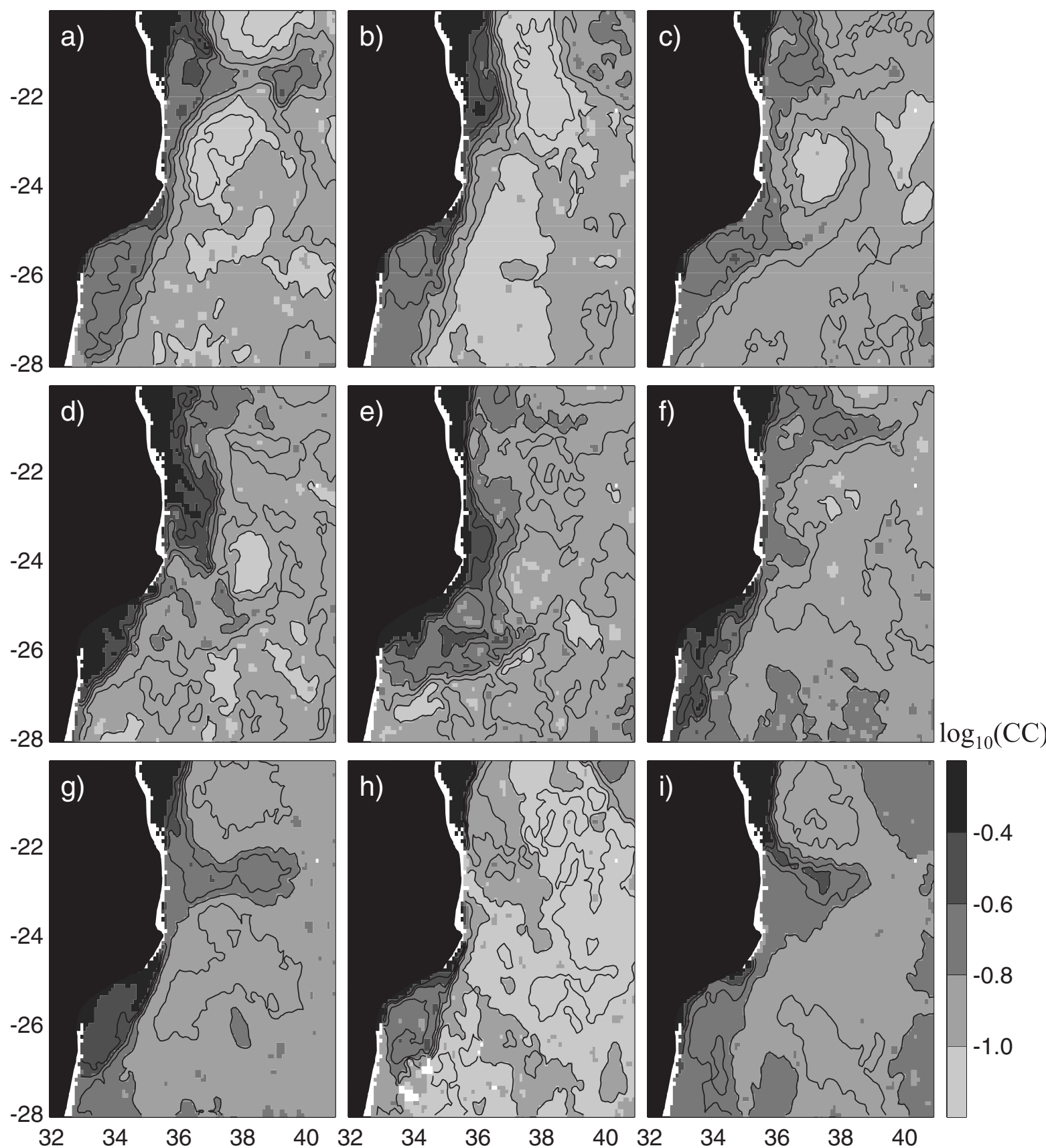

Figure 5. A number of 6-day chlorophyll composites for the southwest Mozambique Channel. a) 9-14th March 1998, b) 21-26th March 1998, c) 2-7th May 1998, d) 22-27th March 2000, e) 3-8th April 2000, f) 3-8th May 2000, g) 21-26th May1999, h) 30th Dec 2001 to 4th Jan 2002, i) 5-10th May 2002. Contour interval is in steps of 0.1 in $\log _{10}(\mathrm{CC})$. 

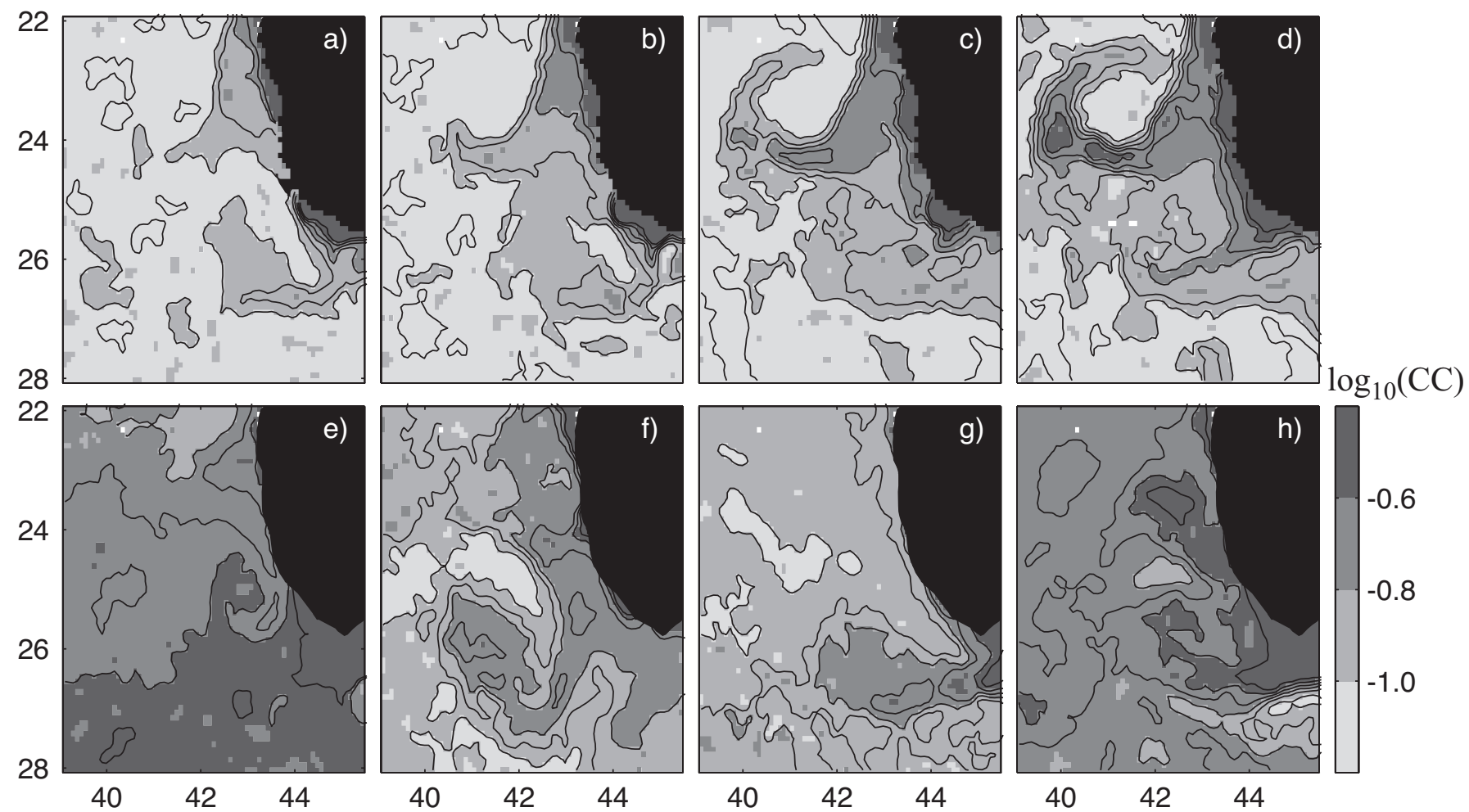

Figure 6. A number of 6-day chlorophyll composites for the southeast Mozambique Channel a) 29th November to 4th December 2000, b) 5-10th December 2000, c) 11-16th December 2000, d) 17-22nd December 2000, e) 19-24th July 1998, 28th January to 2nd February 2000, g) 19-24th October 2001, h) $10-15$ th June 2002. Contour interval is in steps of 0.1 in $\log _{10}(C C)$.
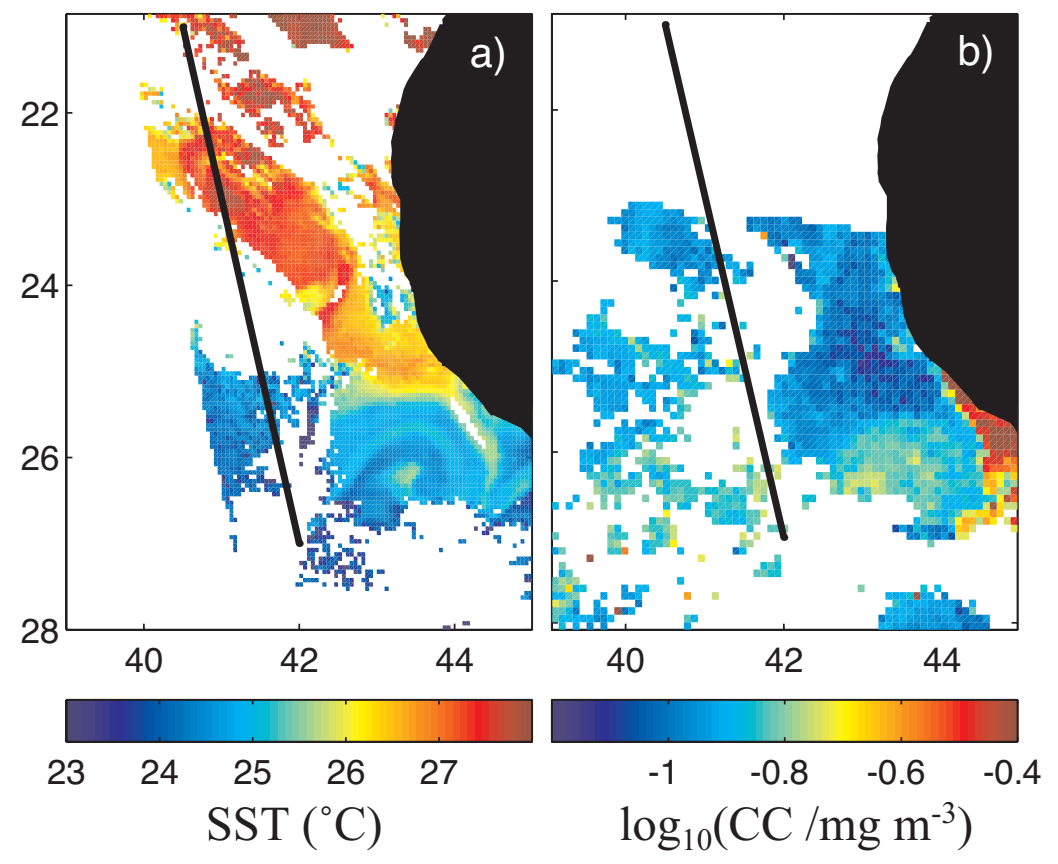

Figure 7. Images showing cyclonic eddy in lee of Madagascar on 11th November 2001. a) SST image from ATSR-2, b) CC images from SeaWiFS. 


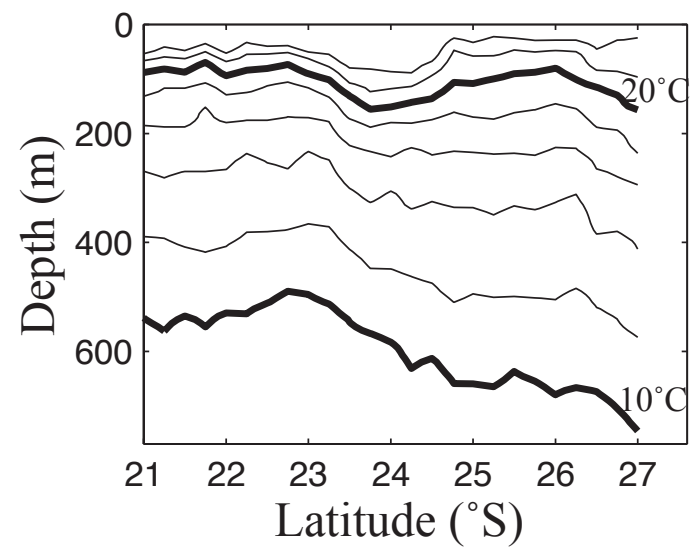

Figure 8. Temperature section from XBTs for 13th-15th Nov. 2001. Data for transect marked on Fig. 7.

Figure 9 (next page)

a)

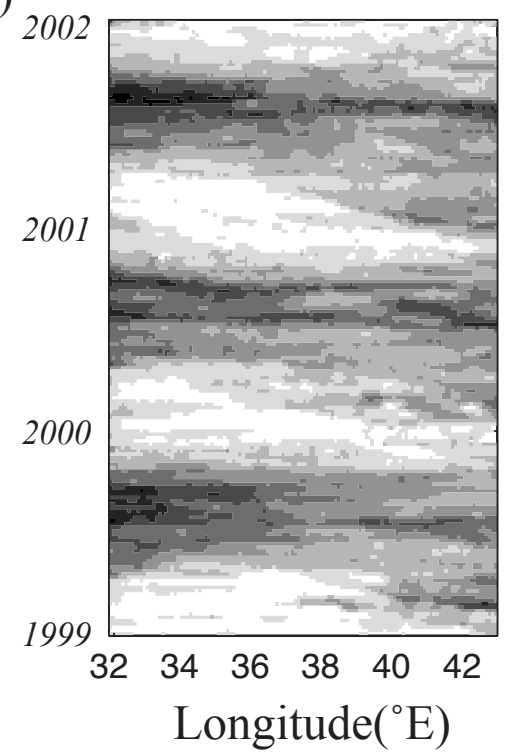

b)

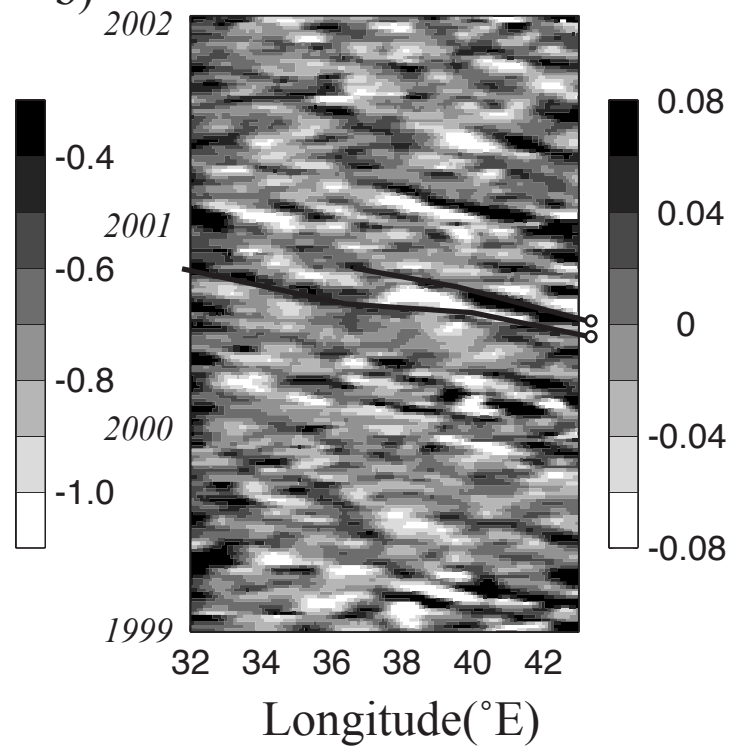

Figure 10. Hovmöller diagrams of $\log _{10}$ of chlorophyll concentration $\left(\mathrm{CC}\right.$, in $\left.\mathrm{mg} \mathrm{m}^{-3}\right)$ for a line running approximately WSW from 43E, 26S (near the southern tip of Madagascar) to $32^{\circ} \mathrm{E}, 30 \mathrm{~S}$ (near Durban). a) CC values showing clear annual signal; b) Filtered values (see text for details), with the trajectories highlighted of the two eddies mapped in Figs. 9a-i. 

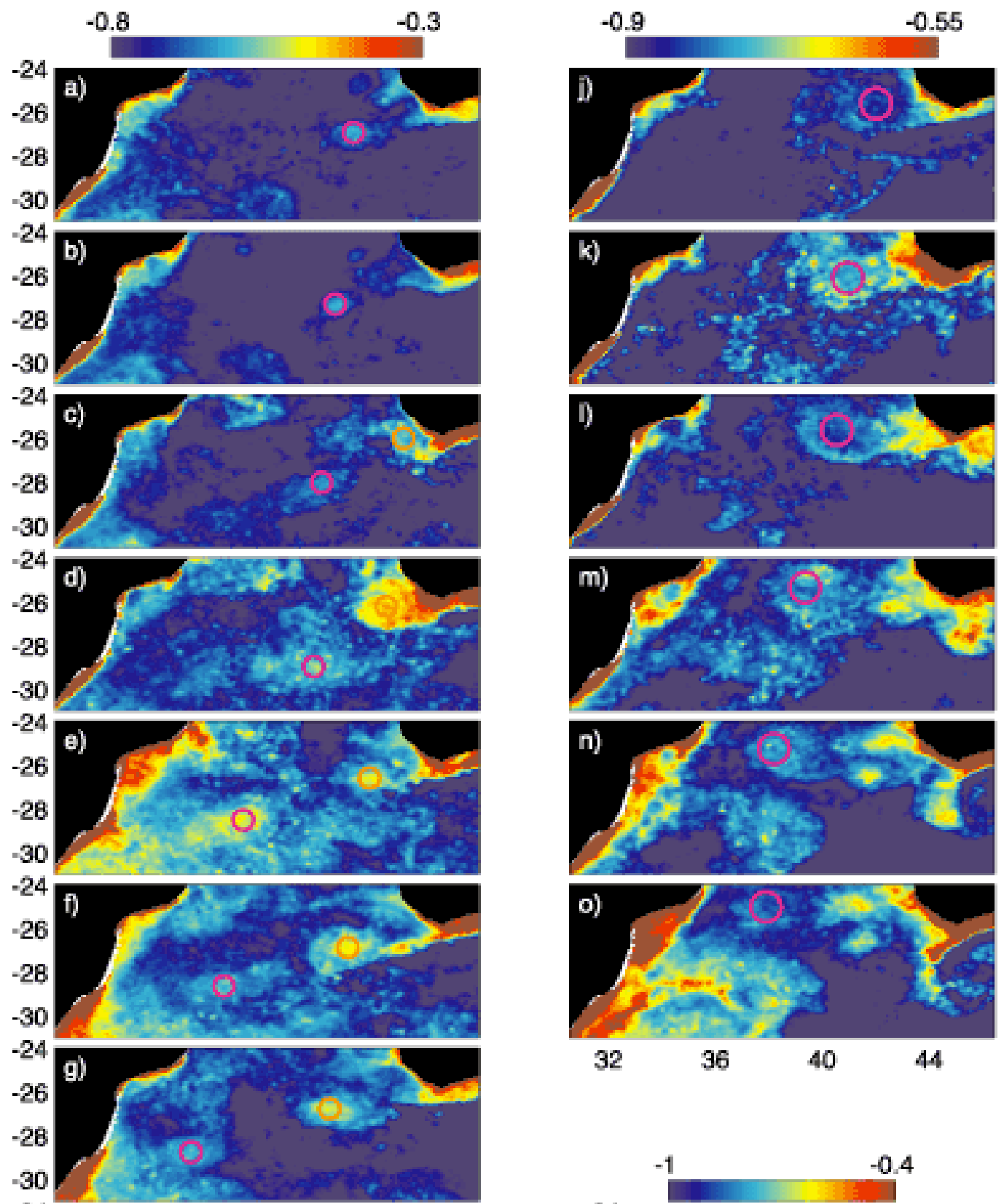

32

36

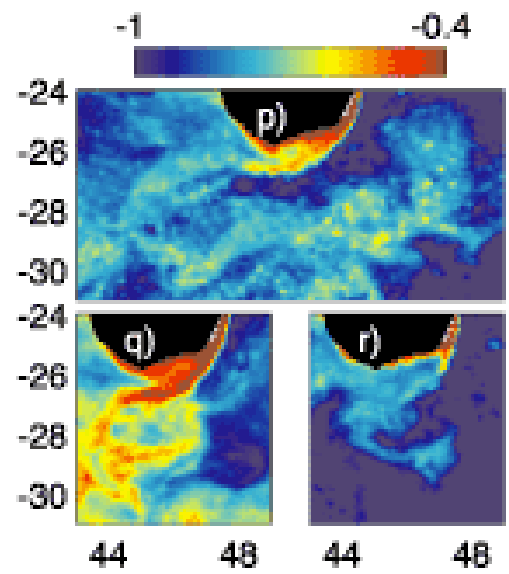

Figure 9. A number of chlorophyll composites for the region to the south of the Mozambique Channel ai) A series of alternate hexads commencing 2-7th June 2000 and finishing 6-11th September 2000, j-o) A series of alternate hexads commencing 29th March to 3rd April 2001 and finishing 28th May to 2nd June 2001, p) 27th April to 2nd May 2000, q) 12-17th September 1999, r) 22-27th January 2000. Note that the colour scale is optimised separately for each of the three series. 